Article

\title{
Spatial Distribution of Energy Consumption and Carbon Emission of Regional Logistics
}

\author{
Fan Xiao ${ }^{1,2}$, Zhi-Hua Hu ${ }^{2, *}$, Ke-Xin Wang ${ }^{3}$ and Pei-Hua Fu ${ }^{4}$ \\ 1 School of Information Engineering Institute, Shanghai Maritime University, \\ Shanghai 200135, China; E-Mail: francy.xiao@139.com \\ 2 Logistics Research Center, Shanghai Maritime University, Shanghai 200135, China \\ 3 School of Economics and Management, Shanghai Maritime University, Shanghai 200135, China; \\ E-Mail: kellyshinee@163.com \\ 4 School of Computer Science and Information Engineering, Zhejiang Gongshang University, \\ Hangzhou 310018, China; E-Mail: fph@zjgsu.edu.cn \\ * Author to whom correspondence should be addressed; E-Mail: zhhu@shmtu.edu.cn; \\ Tel./Fax: +86-21-5885-5200.
}

Academic Editor: Marc A. Rosen

Received: 25 March 2015 / Accepted: 30 June 2015 / Published: 15 July 2015

\begin{abstract}
Facing serious energy-related constraints and environmental stress, the development of the green logistics industry is restricted by degrees of logistics energy utilization and carbon emissions. Considering different logistics spatial distributions, this paper uses the degree of regional logistics energy utilization and the spatial distribution of carbon emissions as two indicators of green logistics to investigate the regional differences and changes in spatiotemporal logistics energy efficiency. We firstly measure the regional logistics in terms of energy consumption and carbon emission, then further measure the logistics by energy intensity and carbon intensity. Based on these four indicators, the relations between spatiotemporal logistics and regional logistics development are analyzed. Through studying the spatial and temporal evolution trends of the above indicators, we found that a certain convergence exists. Finally, based on the analysis, the suggestions for energy saving and emission reduction are proposed according to regional conditions. The results benefit to narrow the efficiency gap between regions and achieve the goal of improving logistics energy efficiency.
\end{abstract}


Keywords: green logistics; energy efficiency; regional logistics; carbon emission; energy consumption

\section{Introduction}

With the development of global economics, the negative environmental consequences brought by accelerated economic activities are becoming increasingly serious. As one of the world's largest energy consumers and carbon dioxide emitters, China is pressured by environment issues. According to the BP Statistical Review of World Energy published in June 2014, China's energy consumption accounts for $22.4 \%$ of global consumption, and $49 \%$ of global growth during the last year. Meanwhile, China's carbon dioxide emissions are greater than that of the European Union and the United States, by up to 10 billion tons [1]. According to the survey data, China's energy consumption of tertiary industry accounts for approximately $30 \%$ of the total energy consumption. Moreover, as the main forms of the logistics industry, transportation, warehousing, and postal service account for more than $80 \%$ of energy consumption of tertiary industry. Thus, the logistics industry is expected to improve its energy efficiency and reduce carbon dioxide emissions for environmental protection.

Because of the situation of energy shortage and environmental deterioration, China's current extensive economic growth model makes the contradiction between economic development and environment increasingly conspicuous. With the rapid growth of the economy, the logistics industry has also rapidly developed in recent years. Furthermore, the logistics industry was incorporated into China's top ten revitalizing industries in 2009. This shows the logistics industry has gradually become an important industry that serves other industries and is strategically significant. As one of the major industries with serious energy consumption, the rising trend of energy consumption in the logistics industry is significant, as shown in Figure 1. It presents the positively correlated relations between logistics energy consumption and economic development. This means the development of the logistics industry can promote economic growth, but it also causes an increase in energy consumption and carbon emissions. Thus, in the concept framework of green logistics recently, energy efficiency and environmental influence have gradually become factors that restrict the sustainable development of this industry. Faced with many factors (e.g., patchy infrastructure, chaotic market management) that affect logistics' economic model with high input and low output in terms of energy, the logistics industry not only has a high benefit of economic output; but also portrays a great negative impact on energy consumption and environmental protection [2]. Thus, in support of environmental policy, the logistics industry has a bright future once a good operation system to reduce energy consumption and carbon emissions is formed.

In the background of the sustained growth of logistics energy consumption, green logistics attracts the attention of various countries. Green logistics emphasizes sustainable development in logistics operations, thereby limiting the negative impacts of logistics on environment and guiding the green development [3]. Thus, energy conservation and emissions reduction can be regarded as two indicators of green logistics, and in the macroscopic perspective, it involves the extents of energy efficiency in the logistics industry. To evaluate the energy utilization preliminarily, the energy intensity is widely used, which is represented by energy consumption (million tons of standard coal) of unit GDP 
(billion) [4]. Figure 2 presents the energy intensity in China. It can be seen that China's overall energy intensity increased initially and then declined from 2002, until reached 1.2 or so in 2011, whereas logistics energy intensity presents an upward tendency from 2001. Even from 2008 to 2011, it also maintained at around 1.77 and had no obvious downward tendency, whereas the decline of the national energy intensity was obvious. The phenomenon shows that although China is trying to reform its economic growth model for the logistics industry, the potential for energy efficiency is still not ideal and energy consumption remains at a high level. Thus, the research of logistics energy efficiency is beneficial for revealing the whole situation of energy utilization in China and exploring possible directions to improve logistics efficiency.

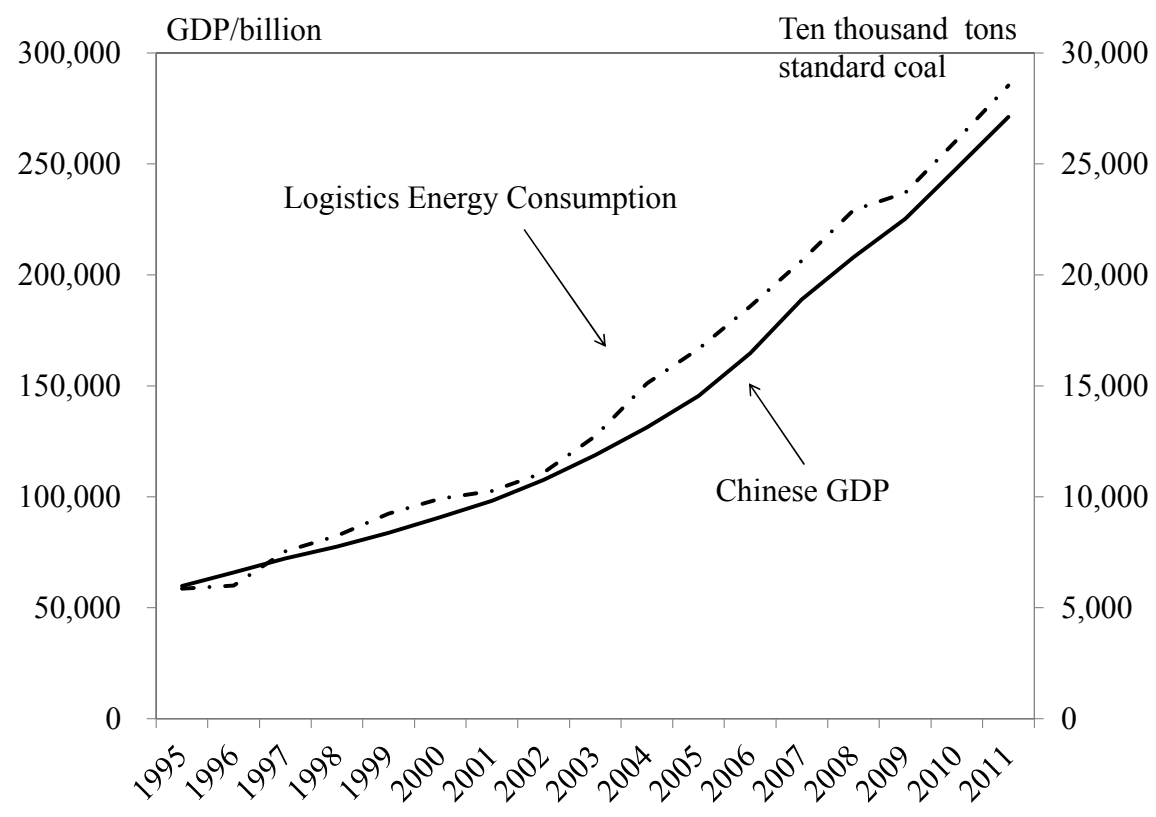

Figure 1. Logistics energy consumption in China (1995-2011).

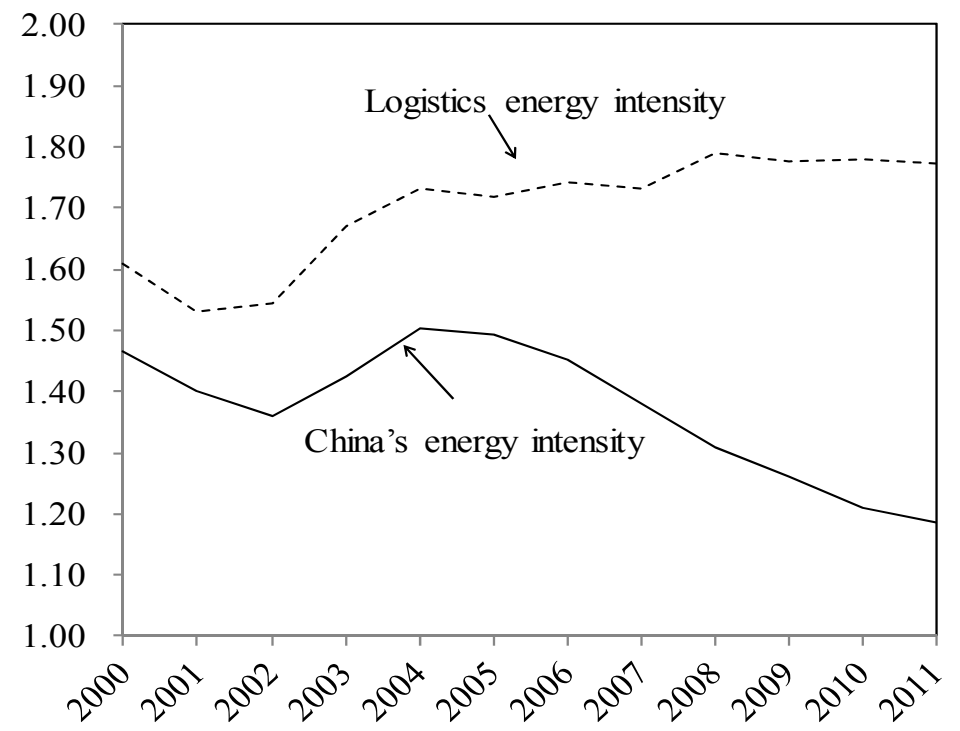

Figure 2. Energy intensity in China (2000-2011). 
Furthermore, low-carbon economy requires that the logistics industry should pay attention to energy efficiency as well as to lowering carbon emissions. Considering global warming, countries all over the world are trying to build a new emission control systems, and China is no exception. As the main industry of carbon emissions, the logistics industry will inevitably undertake tremendous pressure to make reductions in the future. According to statistical data, the energy consumption of transportation, warehousing, and postal service focuses on oil consumption, and there is still a certain proportion of coal energy used in parts of regional logistics industry. The structure of energy consumption is very unreasonable [5]. In 2011, it accounted for $38 \%$ of the total passenger and freight turnover [6]. Thus, the structure of transportation still needs to be optimized. Above all, the research of energy utilization efficiency of logistics based on the carbon emission constraint has benefits for revealing China's current situation of carbon emission in the logistics and for adjusting and controlling its direction.

Additionally, China's economic development has obvious regional characteristics, and regional logistics systems with regional differences leads to differences in logistics energy efficiencies. A regional logistics system involves in multi-domains, e.g., economy, technology and social development, which is closely related to the relations between regions, within regions, industrial structure, and logistics models. On the one hand, the development of regional logistics must rely on the promotion of the regional economy; on the other hand, the inherent mechanisms of regional economics also affects green logistics [7]. Thus, it is necessary to promote the development of green logistics. In the background of the complex economic environments, the operational regional logistics system must be emphasized. However, China is developing and the differences of the developing levels of the regional green logistics lead to the situation where planning policy of the logistics industry must be based on regional development. Decision-makers should deeply understand the relations between regional green logistics, economic development and spatial distribution characteristics, so that the logistics development policies can be adjusted according to local conditions. Thus, it is beneficial to reveal the development characteristics of the green degree of the regional logistics system through studying the relations between energy efficiency and economic development, spatial distribution models, and the main factors causing the regional difference.

Based on the above analysis, China is used as the research background. Three aspects are investigated to study the connotations of regional green logistics: logistics energy consumption, carbon emissions, and their spatial distribution. Consideration of different geographical regions, factors including the structure of regional economy, logistics energy consumption, transportation models and so on, are discussed. Thus, this study contributes to the literatures in the following aspects. First, considering the spatiotemporal characteristics of regional logistics, we analyze the trend of logistics energy efficiency changing with time and the regional difference of logistics energy efficiency, which offsets the deficiency that only pays attention on one-year static data or ignore spatial factors. Second, based on geography information systems (GIS) and empirical study, we analyze different mechanisms for many external factors affecting logistics energy efficiency and its fluctuation characteristics, according to the geographical division (e.g., eastern, central, and western).

The rest of the study is organized as follows. In Section 2, the studies related to green logistics, carbon emissions, and spatial distribution are reviewed. Then in Section 3, the methods of measuring energy consumption and carbon emissions are introduced for regional logistics. The data is described and analyzed in Section 4. Finally, we conclude the study in Section 5. 


\section{Related Studies}

Economic growth promotes the development of the logistics industry. The environmental benefits of logistics activities gradually get extensive publicity from the international communities. Thus, green logistics has become an important research subject. In the green logistics and supply chain management field, Zhang and Zhao [8] put forward a specific management strategy for government and enterprises aimed at the principles of green packaging. Government can enact specialized tax system to encourage enterprises to package on a large scale and use the materials that are green and recyclable. To help manufacturing companies achieve sustainability performance, Chin et al. [9] proposed a plausible conceptual model to elucidate the relations between green supply chain management, environmental collaboration, and sustainability performance. Kuei et al. [10] studied the critical factors that influence the adoption of green supply chain practices in Chinese firms. By analyzing the data, they found that external environmental factors including customer pressures, regulatory pressures, government supports, and environmental uncertainty were the most important in adopting green practices. Gunasekaran [11] discussed the current trends and future research directions in green supply chain collaboration and incentives. Sheu et al. [12] presents an optimization-based model to deal with integrated logistics operational problems of green-supply chain management (G-SCM). Used-product reverse logistics in his given green-supply chain was considered. Besides, to describe green logistics quantitatively, many scholars always adopt the way of calculating the energy consumption and greenhouse gas emission in the logistics process. Zhang and Wei [13] examined the dynamic changes in total carbon emission performance within the transportation sector in China, by considering regional heterogeneity. Through using the new total factor index, they found carbon emissions increased $6.2 \%$ for the 2000-2012 periods. Fahimina et al. [14] presented a tactical supply chain planning model that can be used to investigate tradeoffs between cost and environmental degradation including carbon emissions, energy consumption, and waste generation. Florian and Igl [15] set up a quantitative distribution network model to study the carbon footprints of 125 scenarios. They concluded that logistics service provider (LSP) structures practicing a geographically decentralized consolidation of shipments are most efficient in reducing of greenhouse gas (GHG) emissions. Thus, it can be seen that the concept of green logistics has enjoyed popular support and it deserves further research.

In this paper, we seek to find out the evaluation indicators to analyze the green degree of logistics industry. Due to the green logistics being a relatively new concept and there not being a clear indicator system used to measure the degree of green logistics, energy consumption and carbon emission become two good indicators for the main negative effects on the environment brought by logistics activity. With the exception of the above work that considered carbon emissions $[13,14]$, there are many other scholars who focus on carbon emission and energy consumption in logistics. For example, based on analysis of the impact of transportation structure on carbon emission, WEI et al. [16] employed a quantitative approach and time series data (1989-2009) to analyze the effect in China. Song and $\mathrm{Xu}$ [17] researched carbon emission in container shipping, and they found that high port handing capacity and efficient empty container repositioning can reduce emissions in seaborne transportation. He et al. [18] estimated the carbon emission and energy consumption from China's urban passenger transportation sector up to year 2030. They presented that promoting public transportation and limiting car usage can contribute $21 \%$ of the total energy reduction of China's 
transportation sector in 2030. Yin et al. [19] explored the future development of China's transportation sector in terms of energy consumption, carbon emission, and service demands. They pointed that transportation carbon emission and energy consumption will continue to increase rapidly without major policy intervention, though carbon price policies may have certain inhibiting effect. Besides, considering logistics activity associated with economic output, logistics energy intensity and carbon intensity, which usually performance on energy efficiency, are also involved in the study of green logistics. Hu and Wang [20] analyzed energy efficiencies of the 29 administrative regions in China for the period 1995-2002 with a newly introduced index system. The data envelopment analysis (DEA) was used to confirm the scenario that energy efficiency increases with economy growth. Zhang et al. [21] proposed a hybrid energy input-output model to analyze the total energy consumption of different regions. They thought that, for industries, developing and energy efficiency is significant; and for developing and energy exporting regions, transforming primary energy into high value-added products would be beneficial for economic development and energy conservation. Caraiani et al. [22] developed investigations on the causal relationship between energy consumption and GDP in the context of emerging European countries covering the period 1980-2013. The results were concluded through empirical study as follows. A balance exits in confirmative conservation, growth and neutrality hypotheses. In some specific cases, energy consumption and economic growth are jointly determined.

Aimed at the characteristic that China is a large country, it is necessary to study the regional features of logistics. Logistics development is affected by the economy for economic development causes more demand for logistics services, meanwhile, it also promotes economic development [23,24]. Thus, to research the regional logistics, it is necessary to connect regional economic development. Dai and Yang [2] analyzed the contribution of logistics park construction to regional economic development. From the perspective of growth pole theory under regional economic theory, they indicated that the logistics park would be a growth pole in certain cities of regions. For the phenomenon that the speed of logistics infrastructure investment in central China is lower than other regions, $\mathrm{Hu}$ et al. [25] pointed that there existed co-integration relations between the regional logistics investment, logistics value-added, and GDP. Connected to carbon emission and energy consumption, Duan [26] built a logistics-induced energy economic hybrid model considering regional characteristics to find the optimal carbon tax in China. By solving the model, the optimal carbon tax was monotonically increasing and S-shaped. Comparing to other country with large areas like the US, their government was investing significant resources in the development of logistics clusters [27]. Due to the influence of small population density and good environment, researchers aimed at other large countries are less attention on carbon emission and energy consumption, and they usually focus on economics and transportation [28]. Nevertheless, the literatures that directly describe regional logistics and economic characteristics in connection with carbon emission and energy consumption are still lacking [29,30]. Thus, the contribution of our work is to link the four parts (regional logistics, economy, energy consumption and carbon emission) and analyze their synergy and inhibition mechanism.

Besides, the research based on spatial distribution of energy consumption is not well studied in literature, especially the logistics energy efficiency. Howard et al. [31] built a model to estimate the building sector's end-use energy intensity for space heating, domestic hot water, electricity for space cooling, and electricity for non-space cooling applications in New York City. Spreng [32] discussed the intra- and international distributions of energy consumption and their implications for 
intergenerational equity. They concluded that we might have already reached or perhaps even surpassed the sustainability limit of energy inequality. Some scholars used GIS in their studies. Therefore, many methods including geographically weighted regression [33] and spatial correlation analysis [34] were introduced. Dujardin et al. [35] analyzed the impact of territorial structures upon energy consumption in the Wakkoon Region and revealed that some rural settlements characterized by low density show good performance in terms of energy efficiency. Li et al. [36] described the spatial dynamic distribution of heavy metals by using GIS; and Mua et al. [37] also used GIS to analyze the distribution of species. From the above literatures, it can be seen that there is still no systematic research aimed at spatial logistics energy efficiency and spatial patterns.

Thus, based on the review of literatures, we introduce GIS to analyze the spatial distribution of energy consumption and carbon emission in logistics industry. Regional economics was used to analyze its relationship with spatial distribution.

\section{Regional Logistic Energy Consumption and Carbon Emission}

The models of measurement method of logistics energy intensity and carbon emissions are demonstrated in Sections 3.1 and 3.2, respectively. The reasonable measurement methods are the basis of evaluating logistics energy efficiency. Moreover, it helps to understand the current stage of Chinese logistics under the condition of energy utilization and carbon emissions.

\subsection{Measuring Logistics Energy Intensity}

According to the General Principles for Calculation of the Comprehensive Energy Consumption published by Standardization Administration of the People's Republic of China (SAC) in 2008, we can design the measurement method of regional logistics energy consumption. Then the energy consumption can be calculated.

(1) Logistics energy consumption

Logistics Energy Consumption ( $L E C$ ) refers to the physical quantity of all kinds of fuels consumed by energy-consuming units in logistics during the studied period of statistics. All types of energy consumption are converted into standard coal. The indicator mainly reflects the total energy consumption level of regional logistics. $L E C$ is determined as Equation (1).

$$
L E C=\sum_{i=1}^{n} e_{i} \times p_{i}
$$

LEC represents logistics energy consumption; $n$ denotes the types of fuels consumed by logistics activity; the amount of fuel $i$ consumed by logistics activity is denoted by $e_{i}$; and the conversion coefficient of fuel $i$ is $p_{i}$ (Table 1 ). 
Table 1. Conversion coefficients for different kinds of fuels.

\begin{tabular}{cc|cc}
\hline Energy Category & Conversion Coefficient & Energy Category & Conversion Coefficient \\
\hline Raw coal & $0.7143 \mathrm{kgce} / \mathrm{kg}$ & Fuel oil & $1.4286 \mathrm{kgce} / \mathrm{kg}$ \\
Clean coal & $0.9 \mathrm{kgce} / \mathrm{kg}$ & Naphtha & $1.500 \mathrm{kgce} / \mathrm{kg}$ \\
Other coal washings & $0.2857 \mathrm{kgce} / \mathrm{kg}$ & Lubricating oil & $1.4143 \mathrm{kgce} / \mathrm{kg}$ \\
Briquette & $0.600 \mathrm{kgce} / \mathrm{kg}$ & Paraffin & $1.3648 \mathrm{kgce} / \mathrm{kg}$ \\
Coke & $0.9714 \mathrm{kgce} / \mathrm{kg}$ & Solvent naphtha & $1.4672 \mathrm{kgce} / \mathrm{kg}$ \\
Coke Oven Gas & $0.5714 \mathrm{kgce} / \mathrm{m}^{3}$ & Petroleum asphalt & $1.3307 \mathrm{kgce} / \mathrm{kg}$ \\
Other Coal Gases & $0.5143 \mathrm{kgce} / \mathrm{m}^{3}$ & Liquefied petroleum gas & $1.7143 \mathrm{kgce} / \mathrm{kg}$ \\
Other coking products & $1.3 \mathrm{kgce} / \mathrm{kg}$ & Refinery dry gas & $1.5714 \mathrm{kgce} / \mathrm{kg}$ \\
Oil & $1.4286 \mathrm{kgce} / \mathrm{kg}$ & Other petroleum products & $1.400 \mathrm{kgce} / \mathrm{kg}$ \\
Gasoline & $1.4714 \mathrm{kgce} / \mathrm{kg}$ & Natural gas & $1.330 \mathrm{kgce} / \mathrm{m}^{3}$ \\
Kerosene & $1.4714 \mathrm{kgce} / \mathrm{kg}$ & Heating power & $0.03412 \mathrm{kgce} / \mathrm{MJ}$ \\
Diesel oil & $1.4571 \mathrm{kgce} / \mathrm{kg}$ & Electric power & $0.1229 \mathrm{kgce} / \mathrm{kw} \cdot \mathrm{h}$ \\
Liquefied Natural Gas & $1.7572 \mathrm{kgce} / \mathrm{kg}$ & Other fuels & $1.00 \mathrm{kgce} / \mathrm{kg}$ \\
\hline
\end{tabular}

Resource: General Principles for Calculation of the Comprehensive Energy Consumption, 2008.

(2) Logistics energy intensity

Based on the measurement method of logistics energy consumption, we introduce the concept of logistics energy intensity to investigate the relations between logistics energy consumption and economic output. Logistics energy intensity is the ratio of energy utilization and economic output, which is commonly used to describe the degree of energy utilization. Some scholars have also conducted, but no scholar has analyzed the energy intensity on the logistics industry in the literatures. Thus, we further calculate China's logistics energy intensity in this section to observe the difference of the change of China's total energy intensity with other countries.

Logistics Energy Intensity [4] refers to the ratio of energy utilization and gross domestic product (GDP) during the studied period. It reflects the logistics energy consumption for per logistics GDP in a country or region, and can be used to measure the relations between logistics development level and logistics energy consumption. The lower value indicates that the efficiency of logistics energy utilization is higher and the economic output is better. $L E I$ is determined by Equation (2), where $L E I$ represents logistics energy intensity; and $G$ represents the GDP of logistics industry during the period of statistical.

$$
L E I=\frac{L E C}{G}
$$

\subsection{Measuring Logistics Carbon Emission}

Due to the method recommended by IPCC can be used to calculate the carbon emissions effectively [38,39], we use the IPCC carbon accounting method to measure the amount of logistics carbon emission, which is formulated as Equation (3).

$$
L C_{s t}=\sum\left(E_{s j t} \times \delta_{s} \times \eta_{i}\right)
$$

Here, $L C_{s t}$ represents the total amount of logistics carbon emissions of the region $s$ in the year $t$; $E_{s j t}$ denotes the amount of energy consumption of the region $s$ in the year $t$; the conversion 
coefficient of energy $i$ is denoted by $\delta_{i}$; and the carbon emission coefficient of energy $i$ is $\eta_{i}$. Table 2 shows the carbon emission factors for different kinds of fuels.

Table 2. Carbon emission factors for different kinds of fuels.

\begin{tabular}{cc|cc}
\hline Energy Category & Carbon Emission Factor & Energy Category & Carbon Emission Factor \\
\hline Raw coal & 0.7559 & Kerosene & 0.5714 \\
Clean coal & 0.7559 & Diesel oil & 0.5921 \\
Coke & 0.8550 & Fuel oil & 0.6185 \\
Other coking products & 0.6449 & Liquefied petroleum gas & 0.5042 \\
Coke Oven Gas & 0.3548 & Refinery dry gas & 0.4602 \\
Other Coal Gases & 0.3548 & Natural gas & 0.4483 \\
Oil & 0.5857 & Other petroleum products & 0.5857 \\
Gasoline & 0.5538 & Electric power & 2.2132 \\
\hline
\end{tabular}

Resource: 2006 IPCC Guideline for National Greenhouse Gas Inventories, 2006.

According to the measuring of logistics carbon emissions, to investigate the relations between logistics carbon emissions and economic output, we can further measure the logistics carbon intensity by Equation (4). Here, $C I$ denotes the carbon intensity; $L C$ is the amount of carbon emissions; and $G$ is the economic output during the period of statistical. The smaller value of $C I$ indicates that the amount of carbon emissions caused by unit logistics GDP is less, and thereby the environmental benefits of unit logistics activity is higher.

$$
C I=\frac{L C}{G}
$$

Through the above indicators related to regional logistics and economics, we define some variables (Table 3) to reveal the present situation, historical trends, and spatial pattern of China's energy utilization and carbon emission.

Table 3. Four energy and carbon emission indicators for regional logistics.

\begin{tabular}{lll}
\hline Symbol & \multicolumn{1}{c}{ Variable } & \multicolumn{1}{c}{ Definition } \\
\hline$L E C$ & $\begin{array}{l}\text { Logistics Energy } \\
\text { Consumption }\end{array}$ & $\begin{array}{l}\text { Actual consumption of all kinds of fuels in logistics } \\
\text { industry (ten thousand tons standard coal) }\end{array}$ \\
\hline$L C$ & Logistics carbon emissions & Carbon emissions in logistics industry (ten thousand tons) \\
\hline$L E I$ & Logistics energy intensity & $\begin{array}{l}\text { Ratio of energy utilization and logistics GDP (ten } \\
\text { thousand tons standard coal/billion yuan) }\end{array}$ \\
\hline$C I$ & Carbon intensity & $\begin{array}{l}\text { Ration of logistics carbon emissions and logistics GDP } \\
\text { (ten thousand tons/billion yuan) }\end{array}$ \\
\hline
\end{tabular}

\section{Data and Analysis (2000-2011)}

Based on the equations in Section 3, we calculate the panel date of China's 30 administrative regions in this section. First, with the time going on, the trends of logistics energy consumption, carbon emissions, logistics energy intensity and carbon intensity, and the relations between these indicators are analyzed. Then, based on ArcGIS platform (www.esrichina-bj.cn), the logistics spatial distribution pattern of energy consumption and carbon emissions are further analyzed. 


\subsection{Data Sources}

Considering the lack of classification system in the logistics industry in China, we use the relevant transportation, warehousing, and postal data to estimate the overall situation of logistics industry, for their increased value accounted for over $80 \%$ of the total increased value of the logistics industry in the past statistical yearbook.

Based on the data availability and empirical study, the panel data of China's 30 administrative regions (not including Hong Kong, Macao, and Taiwan) is used as study sample for the period 2000-2011. To ensure the quality of sample data, the logistics energy consumption and carbon emissions of Tibet have not been calculated because of the lack of statistical data (especially energy-related data). Energy-related data is from the China Energy Statistical Yearbook [40], and economic-related data is from China Statistical Yearbook [41].

\subsection{Trends of Logistics Energy Consumption, GDP and Carbon Emission}

According to the measure method described in Section 3, we can get results (Table 4), which are the values of four variables ( $L E C, L E I, L C$ and $C I$ ) for the period 2000-2011. Figure 3 shows the trends of logistics energy consumption and carbon emissions. In the results, China's logistics energy consumption, logistics economic output and carbon emissions all sustained growth whose average growth rates are $10.09 \%, 9.12 \%$ and $12.9 \%$, respectively. The convergence trends of the three indicators are significant. In 2011 , the logistics total energy consumption is 285.35 million tons of standard coal, which is 2.9 times of that of 2000; meanwhile, logistics carbon emissions reaches to 162.99 million tons, which is 3.8 times of that of 2000. Observing the changes in three types of indicators (Figure 4), the growth rates roughly showed an increasing tendency before 2005, and the growth rates of logistics energy consumption and carbon emissions are significantly higher than the growth rate of logistics GDP. Thus, China's energy input has not obtained a satisfactory economic output in the logistics industry. To the contrary, the energy input aggravated the negative environmental consequences. Then from 2005 to 2011, the growth rates of all types' indicators continued to decrease, and had obvious convergence trends. Especially in 2009, the downtrend was significant, which related to the financial crisis in 2008-2009. After that, the growth began to rise. The growth rates of logistics energy consumption and logistics GDP kept at about 10\%, and logistics carbon emissions kept at about $8 \%$. The situation tends to be stable.

Table 4. Measures for $L E C / L E I / L C / C I$ (2000-2011).

\begin{tabular}{ccccc|ccccc}
\hline Year & $\boldsymbol{L E C}$ & $\boldsymbol{L E I}$ & $\boldsymbol{L C}$ & $\boldsymbol{C I}$ & Year & $\boldsymbol{L E C}$ & $\boldsymbol{L E I}$ & $\boldsymbol{L C}$ & $\boldsymbol{C I}$ \\
\hline 2000 & 9916.12 & 1.61 & 4290.75 & 0.7 & 2006 & 18582.72 & 1.74 & 10877.87 & 1.02 \\
2001 & 10257.08 & 1.53 & 4950.12 & 0.74 & 2007 & 20643.37 & 1.73 & 12098.24 & 1.01 \\
2002 & 11086.49 & 1.54 & 5447.44 & 0.76 & 2008 & 22917.25 & 1.79 & 13236.52 & 1.03 \\
2003 & 12740.1 & 1.67 & 6466.42 & 0.85 & 2009 & 23691.84 & 1.78 & 14039.08 & 1.05 \\
2004 & 15104 & 1.73 & 7392.39 & 0.85 & 2010 & 26068.47 & 1.78 & 15124.17 & 1.03 \\
2005 & 16671.81 & 1.72 & 9844.31 & 1.01 & 2011 & 28535.5 & 1.77 & 16299.49 & 1.01 \\
\hline
\end{tabular}




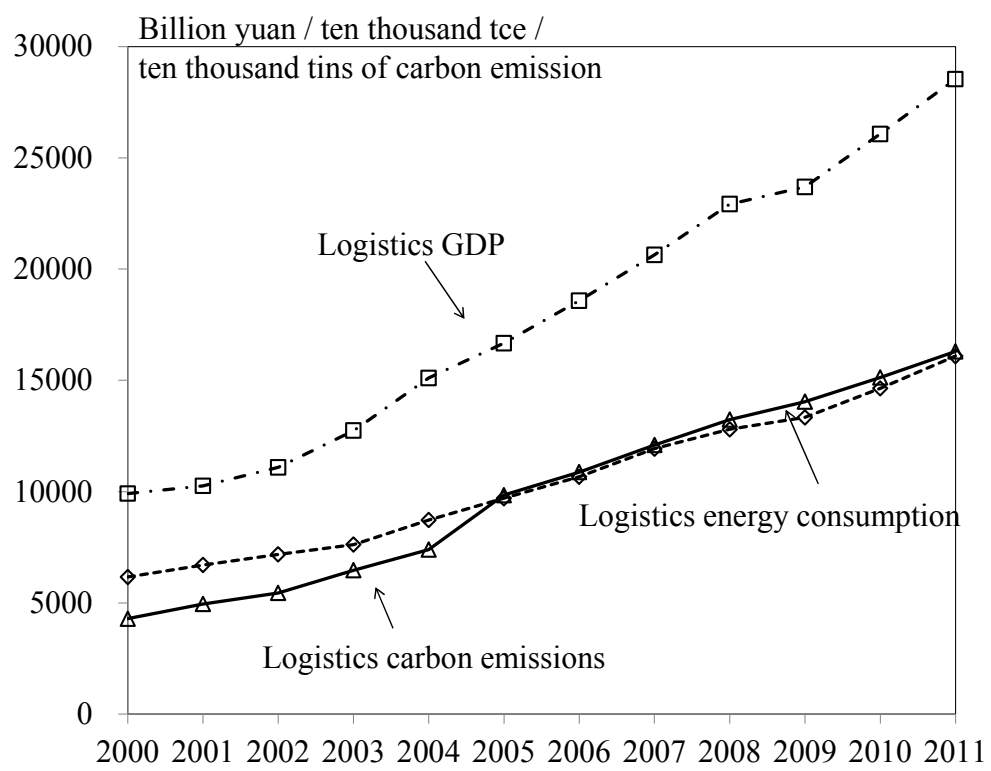

Figure 3. Trends of logistics energy consumption and carbon emissions.

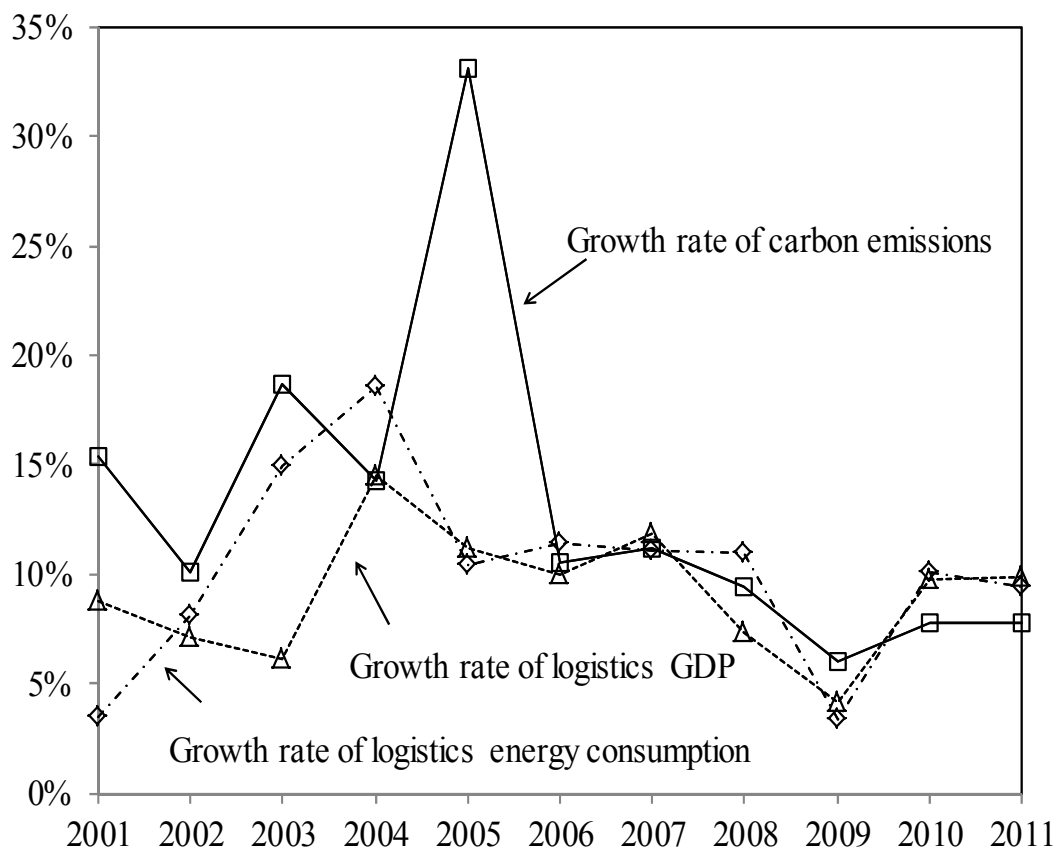

Figure 4. Trends of indicators' growth rates.

The trend of China's logistics energy intensity is affected by energy consumption and the change of logistics demands. Figure 5 shows the trends of China's energy intensity, logistics energy intensity and carbon intensity, whose growth rates are $-1.93 \%, 0.89 \%$ and $3.47 \%$, respectively. Since 2004, China's energy intensity was decreasing, with the proposal of Chinese Eleventh Five-Year Plan (2006-2010) which included a 20\% reduction in energy intensity per unit of GDP compared with Tenth Five-Year Plan (2001-2005). In terms of energy utilization, the technology progress and the update of management concept all can promote social energy efficiency. Especially many heavy manufacturing industries (e.g., metallurgy, steel, power), which have experienced more than 30 years of reform and openness, have initially formed recycle and reuse methods by studying western technology and management 
experience, which led to a downward trend of China's energy intensity overall. However, as a newly developed industry in China, the development of logistics industry is limited by many factors, which reflects on the change of logistics energy intensity for that did not obviously decline. In addition, carbon intensity also did not obviously decline. In the past five years, logistics energy intensity floated around 1.77, but carbon intensity kept at around 1.0. The phenomenon indicates that China's energy consumption and carbon emissions consumed by unit, logistics' economic output is still at a high level, and technical limitations, backward management and unreasonable regulations could lead to the value of indicators staying at a high level. Figure 6 presents a trend of growth in energy intensity. From the figure, we can see that the growth rate of carbon intensity was positive before 2010, and then it turned into a negative. Before 2006, the growth rate of carbon intensity has fluctuated, violently, related to the requirement for economic growth during Tenth Five-Year Plan (2001-2005). When there is a contradiction between economic growth and environmental protection, some departments and local governments always give priority to economic growth firstly, and then the deterioration of environment. After the deterioration of environment, the control of carbon emissions would be considered briefly. Overall, it is because of incomplete environmental protection policy. After which it becomes stable. It related to the influence of the new series of policies and regulations, for following the circumstances of energy conservation and emission reduction all over the world. In addition, the growth rate of logistics energy intensity is invariably at around $0 \%$ in recent years. Thus, although the effect of energy conservation and emission reduction in transportation industry has been vigorously promoted in China, logistics energy intensity has not substantially improved. The downward trend is not clear, and energy investment cost per unit of economic output is still high.

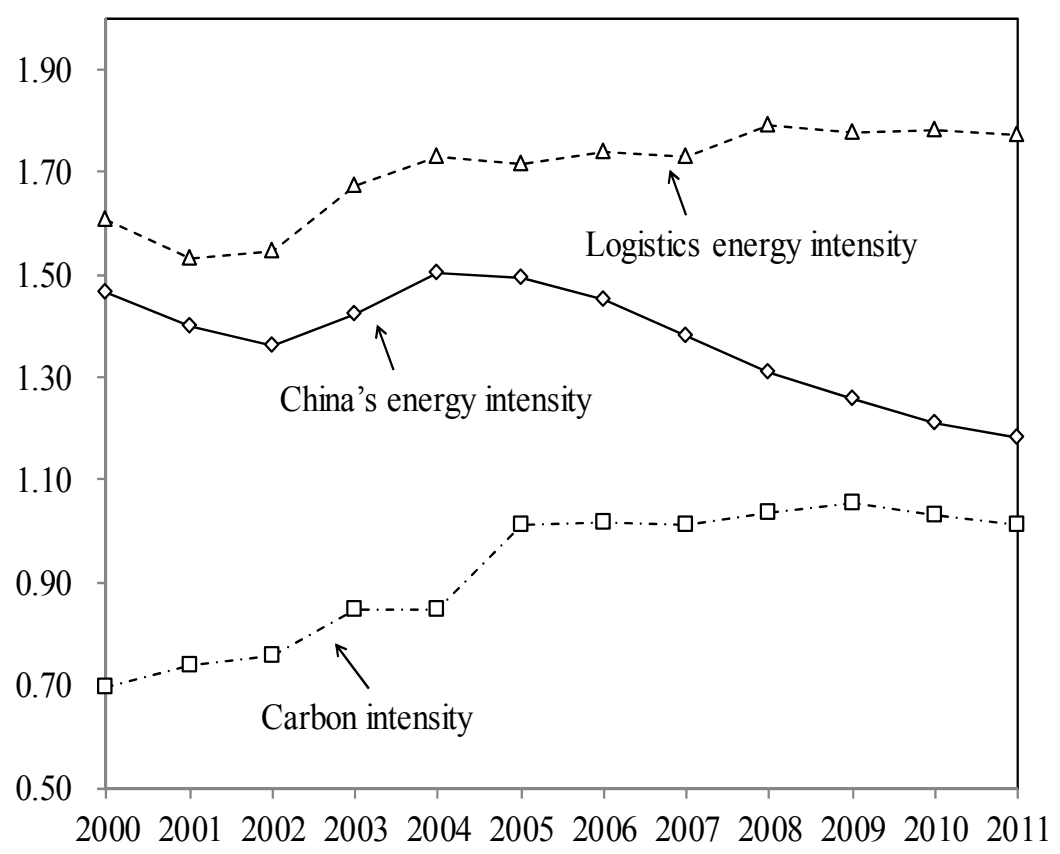

Figure 5. Trends of each energy intensity. 


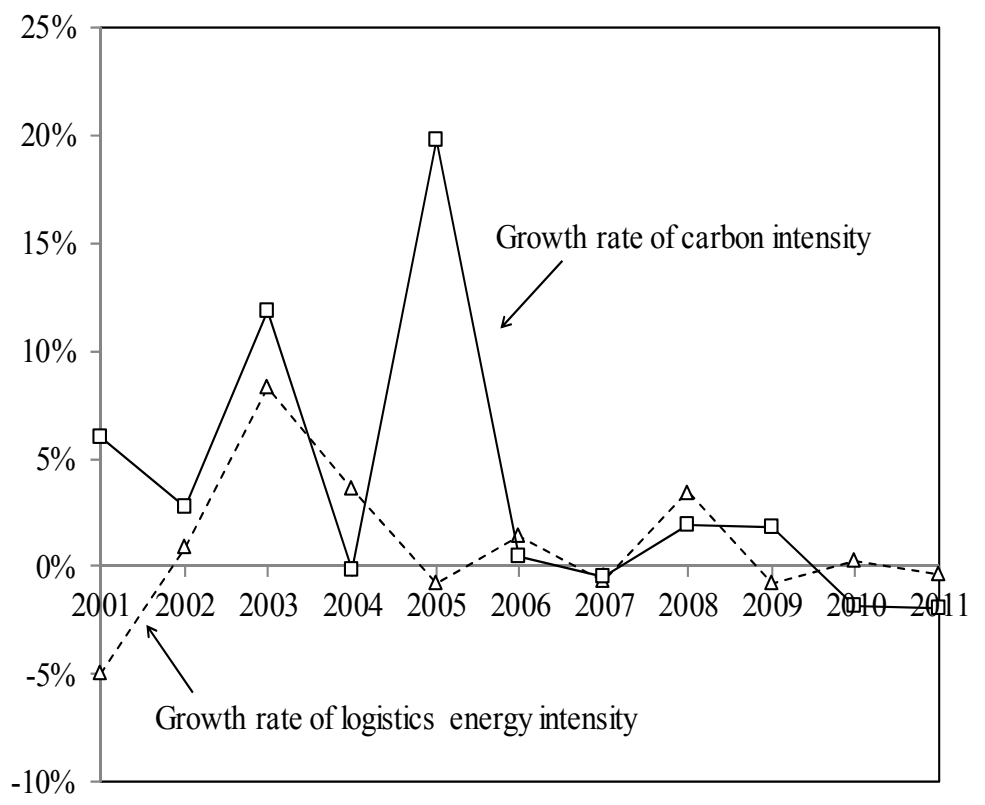

Figure 6. Trends of each indicator's growth rate.

According to Equations (2) and (4), logistics energy intensity and carbon intensity are determined by logistics GDP, energy consumption, and carbon emissions. Nevertheless, in essence, the energy intensity is determined by technical and management capability, and the external policy environment. With the development of those factors, such as the innovation of energy technologies and the improvement of carbon technology, logistics energy-consuming units could gradually reduce the energy consumption but that is still not enough to cope with the growing logistics business. Thus, the energy intensity and carbon intensity still need to decrease gradually. We can think that energy intensity and logistics demands determine the level of logistics energy consumption. Based on the above analysis, China's high logistics intensity and carbon emissions are caused by technology, management, and related policy and regulations.

\subsection{Spatial Distribution of Logistics Energy Consumption and Carbon Emission}

In Section 4.3, we analyze the evolution of China's logistics energy consumption and carbon emissions over time, but the spatial distributions of related indicators are not involved. Thus, we explore the regional difference of logistics' energy consumption and the spatial pattern based on ArcMap (www.esrichina-bj.cn) in this section.

Table 5 shows the measured value of energy consumption, energy intensity, carbon emission and carbon intensity of the logistics industry in 30 administrative regions in 2011 . The provinces with the highest logistics energy consumption are Guangdong, Shandong, and Liaoning. Among them, the consumption of Guangdong is up to 26.2 million tons of standard coal. These regions are mainly distributed in eastern coastal China, which needs a lot of energy consumption to support the huge logistics demands. The high consumption also caused high logistics carbon emissions. The amount of carbon emissions in Shandong and Guangdong with the highest carbon emissions are 15.298 tons and 15.248 tons, respectively. In addition, Yunnan, Hainan, and Shanghai are the top three regions with the highest logistics energy intensity that are up to 4.07, 2.49 and 2.18, respectively. It shows that these 
regions consumed massive energy per unit of logistics GDP output. Similarly, the carbon intensities of the three regions are also of the highest, which indicate that the logistics activity caused great environmental pollution.

Table 5. Regional measures for $L E C / L E I / L C / C I$ (2000-2011).

\begin{tabular}{ccccc|ccccc}
\hline Region & $\boldsymbol{L E C}$ & $\boldsymbol{L E I}$ & $\boldsymbol{L C}$ & $\boldsymbol{C I}$ & Region & $\boldsymbol{L E C}$ & $\boldsymbol{L E I}$ & $\boldsymbol{L C}$ & $\boldsymbol{C I}$ \\
\hline Beijing & 926.23 & 1.14 & 533.09 & 0.66 & Henan & 1119.56 & 1.16 & 569.21 & 0.59 \\
Tianjin & 448.47 & 0.71 & 266.23 & 0.42 & Hubei & 1445.03 & 1.66 & 862.33 & 0.99 \\
Hebei & 826.63 & 0.40 & 499.49 & 0.24 & Hunan & 920.80 & 0.97 & 542.97 & 0.57 \\
Shanxi & 766.72 & 1.01 & 428.91 & 0.57 & Guangdong & 2619.67 & 1.25 & 1524.76 & 0.73 \\
Inner Mongolia & 1315.40 & 1.26 & 776.44 & 0.75 & Guangxi & 774.74 & 1.32 & 455.75 & 0.77 \\
Liaoning & 1700.90 & 1.49 & 931.70 & 0.82 & Hainan & 297.89 & 2.49 & 174.74 & 1.46 \\
Jilin & 478.02 & 1.14 & 287.06 & 0.68 & Chongqing & 551.14 & 1.21 & 329.18 & 0.72 \\
Heilongjiang & 836.05 & 1.54 & 523.15 & 0.96 & Sichuan & 1104.88 & 1.73 & 461.55 & 0.72 \\
Shanghai & 1896.17 & 2.18 & 1107.28 & 1.28 & Guizhou & 514.97 & 0.87 & 302.90 & 0.51 \\
Jiangsu & 1398.56 & 0.66 & 809.67 & 0.38 & Yunnan & 883.15 & 4.07 & 520.92 & 2.40 \\
Zhejiang & 1185.58 & 0.98 & 691.54 & 0.57 & Shaanxi & 838.76 & 1.52 & 502.43 & 0.91 \\
Anhui & 520.45 & 0.88 & 311.63 & 0.53 & Gansu & 299.18 & 1.07 & 187.92 & 0.67 \\
Fujian & 794.48 & 0.82 & 465.59 & 0.48 & Qinghai & 106.72 & 1.58 & 64.61 & 0.96 \\
Jiangxi & 461.57 & 0.91 & 272.24 & 0.54 & Ningxia & 132.18 & 0.76 & 78.76 & 0.45 \\
Shandong & 2587.57 & 1.11 & 1529.81 & 0.66 & Sinkiang & 496.20 & 1.93 & 287.64 & 1.12 \\
\hline
\end{tabular}

Based on the above analysis, we can conclude that the distribution patterns of logistics energy consumption and carbon emissions are similar. To confirm the conclusion, a scatter diagram (Figure 5) was drawn to observe the correlation between the two indicators easily. It shows the two indicators have obvious positive correlation. That is, regions with high logistics energy intensity also have higher carbon intensity.

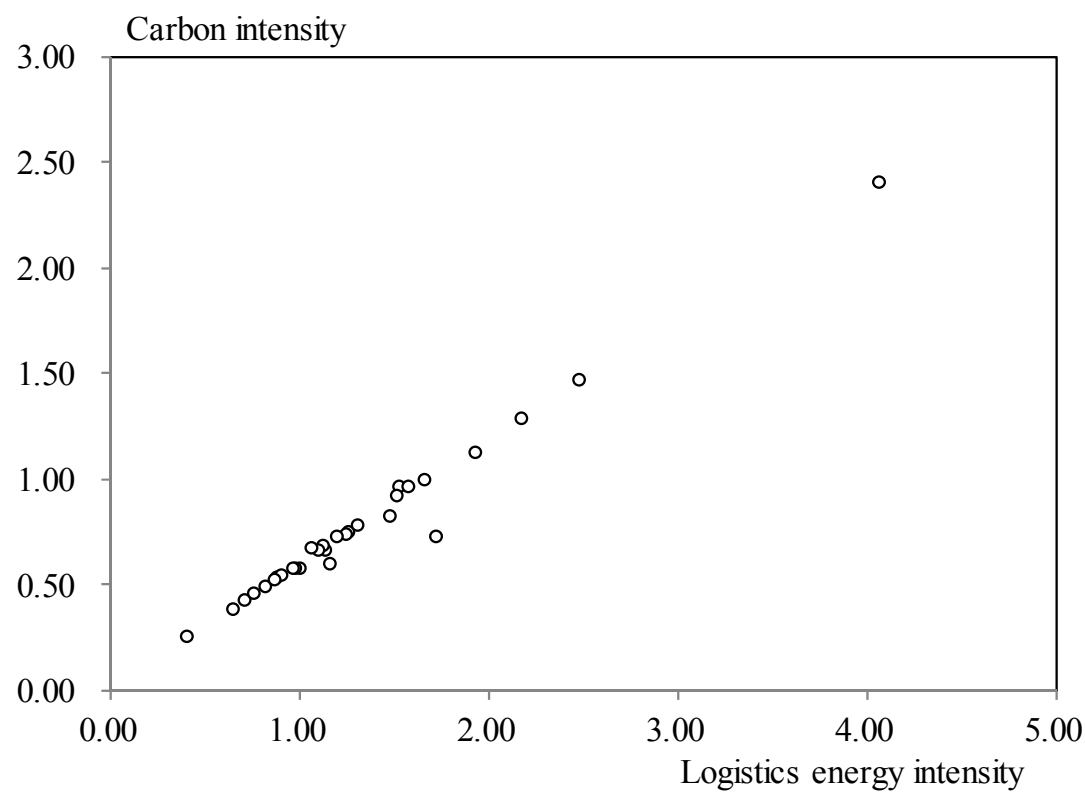

Figure 7. Scatter plots of $L E I$ and $C I$. 
To reveal the spatial pattern of the logistics energy intensity and carbon emissions further, we draw a series of maps that reflect the logistics energy intensity and carbon emissions in 2001, 2006 and 2011 based on ArcMap (Figure 8). The intensities are divided into five levels. If the region's color is deeper, the intensity is higher compared to other regions during the period of research. The dark regions represent the low energy utilization efficiency and poor environmental benefits.

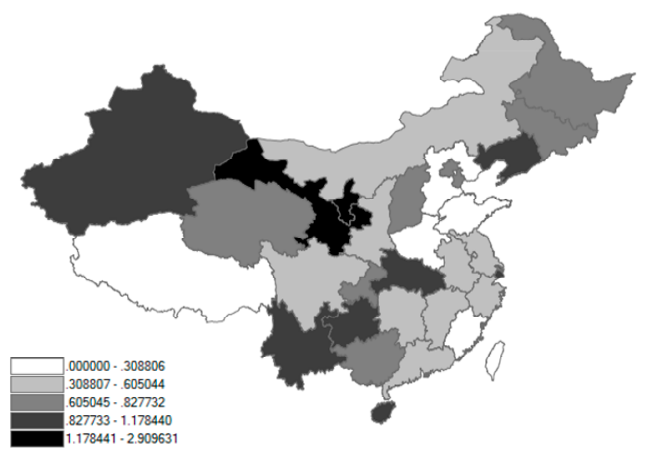

Spatial distribution of logistics carbon intensity in 2001

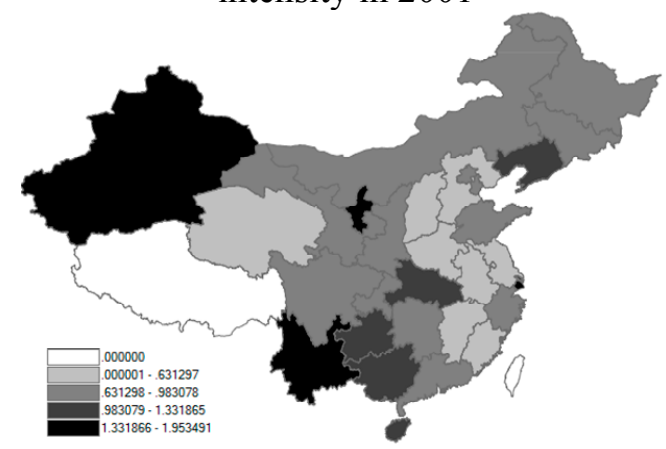

Spatial distribution of logistics carbon intensity in 2006

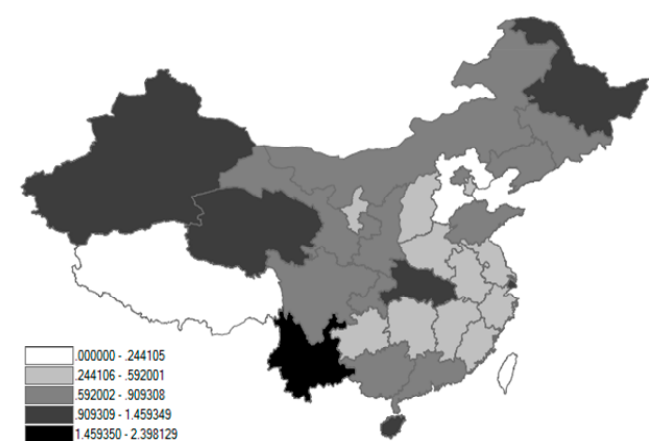

Spatial distribution of logistics carbon intensity in 2011

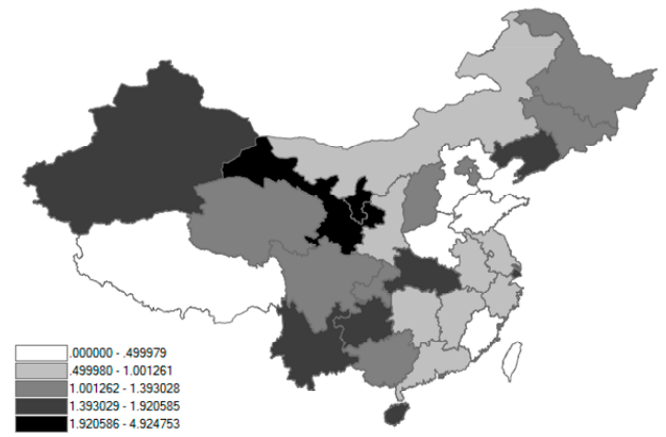

Spatial distribution of logistics energy intensity in 2001

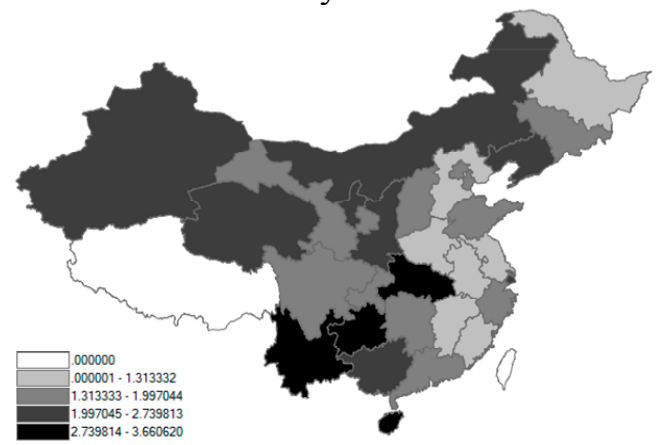

Spatial distribution of logistics energy intensity in 2006

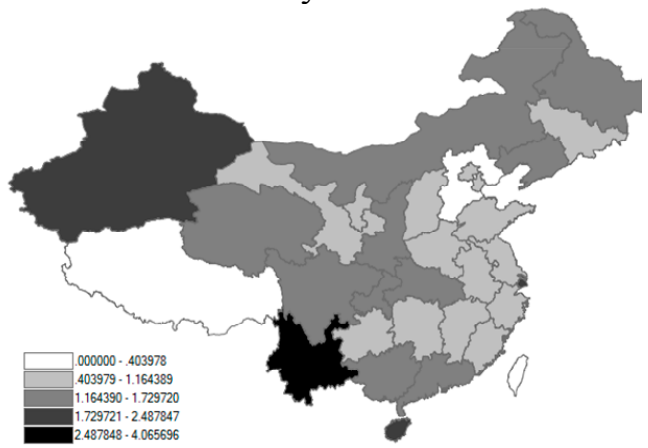

Spatial distribution of logistics energy intensity in 2011

Figure 8. Spatial distribution of $C I$ and $L E I$.

The logistics energy intensity and carbon intensity share a consistent spatial distribution pattern (Figure 8). That is, when the regional energy intensity is high, the carbon intensity of the region is also in a high level. From the perspective of regional distribution, the eastern regions especially in the economic circle of inshore-developed cities always have low logistics energy intensity and carbon emissions, but Shanghai and Hainan are exceptional. The regions' of the Midwest are significantly higher than the 
east, especially Yunnan, Xinjiang, Ningxia and Gansu, which were at high levels in previous years. Their logistics energy efficiency and environmental impact are not optimistic, and it is urgent to conduct energy conservation and emissions reduction.

For the consistent spatial distribution pattern in two indices, it can be considered that high logistics energy intensity means low logistics economic output as well as low energy efficiency, so energy would be wasted and even cause serious carbon emissions. For the regional difference, it is closely related to policy, regional energy consumption structure, production technology, economic development, etc. The energy efficiency for different energy is not the same, for instance, the utilization efficiency of oil and gas is much higher than coal. As the regions with high logistics carbon intensity and energy intensity like Xinjiang, their coal consumption is more than $70 \%$ of total energy consumption according to China Statistical Yearbook [41] in 2011. On the contrary, the "West-to-East Gas Pipeline" produces clean energy of natural gas that is used by the eastern coastal cities widely, which optimized regional logistics energy structure and reduced logistics energy intensity and carbon intensity. Besides, the capacity eliminated by the eastern coastal cities will transfer to the Midwest also leading to the regional difference. On the other hand, the geographical positions for eastern cities are beneficial to absorb foreign technology and management experience to improve economic output. Expertly, Shanghai's logistics energy consumption is staying at a high level, which can be roughly attributed to its special economic geography. Although its logistics GDP is higher than other regions, excessive energy consumption leads to the results that its logistics energy intensity and carbon intensity are higher than the other eastern coastal regions. In addition, many external factors may lead to this abnormal result. The deep-seated reasons for high logistics energy consumption in Shanghai can be studied further. Overall, rational policies, optimized logistics energy structure, and an advanced economy are beneficial to reduce logistics energy intensity and logistics carbon intensity.

\section{Conclusions}

As the revitalizing industry in China, logistics industry plays a key role in economic development. The methods of optimizing energy utilization and reducing environmental impact in the logistics industry are important to promote the development of green logistics systems. This paper measures the value of logistics energy consumption and carbon emissions. Further, to describe the relations between logistics industry and economic development, the logistics energy intensity and carbon intensity are examined. Then, from the perspective of time and space dimensions, we analyze the trends of four types of indicators ( $L E C, L E I, L C, C I)$, and reveal the specific situation of energy utilization impact on the environment. The main conclusions of this study involve the following features. First, logistics energy consumption and carbon emissions have positive correlations with economic development, and the scale expands continuously. Second, the negative environmental impact of logistics activities is expanding, when corresponding logistics economic output is created in China, for the growth rates of logistics energy consumption and carbon emissions are significantly higher than the growth rate of logistics GDP. Third, logistics energy intensity and carbon intensity remained at high levels in recent years, and the trends of decline are not obvious for factors involving technology, management, and environment institutions. Finally, the spatial distribution patterns of logistics energy intensity and 
carbon emissions are similar, where a certain space aggregation effect exists. The increasing tendency from east to west can be roughly concluded.

Based on the empirical results, the following suggestions are to be considered for relevant departments. First, energy management systems for energy conservation and emissions reduction in logistics industry can be established, such as carbon taxes and compensation policy for energy consumption and emissions reduction. Second, different goals of logistics energy efficiency should be established according to the regional economic differences. Thirdly, the structure of logistics energy consumption should be optimized and the development of new energy should be promoted, such as natural sun, wind, and bioenergy. Finally, the industrial structure should be optimized. Relevant policies should consider the central and western regions, so that high value-added industries and regional logistics value-added services are developed with high priority. As for the future research direction, the regional logistics energy efficiency can be evaluated by various methods, and the relations between regional logistics energy efficiency, economy, and development will be investigated.

\section{Acknowledgments}

This study is partially supported by the National Nature Science Foundation of China (71101088, 71471109), the Science Foundation of Ministry of Education of China or Shanghai (20113121120002, 14YZ100, 13SG48), the ministry of transport of the People's Republic of China (2015329810260), and Zhejiang Provincial Natural Science Foundation of China (LZ14G020001).

\section{Author Contributions}

Zhi-Hua $\mathrm{Hu}$ promoted the research and designed the whole framework with Pei-Hua Fu, who is familiar with the background of regional logistics and carbon emissions. Fan Xiao devoted herself to the research on modeling and analysis, and wrote the whole paper. Ke-Xin Wang anticipated in collecting and processing the data, and assisted Xiao to write and optimize the work. All authors have read and approved the final manuscript.

\section{Conflicts of Interest}

The authors declare no conflict of interest.

\section{References}

1. Friedlingstein, P.; Andrew, R.M.; Rogelj, J.; Peters, G.P.; Canadell, J.G.; Knutti, R.; Luderer, G.; Raupach, M.R.; Schaeffer, M.; Vuuren, D.P.V.; et al. Persistent growth of $\mathrm{CO}_{2}$ emissions and implications for reaching climate targets. Nat. Geosci. 2014, 7, 709-715.

2. Dai, Q.; Yang, J. Input-output Analysis on the Contribution of Logistics Park Construction to Regional Economic Development. Procedia 2013, 96, 599-608.

3. Zhang, S.; Lee, C.K.M.; Chan, H.K.; Choy, K.L.; Wu, Z. Swarm intelligence applied in green logistics: A literature review. Eng. Appl. Artif. Intell. 2015, 37, 154-169. 
4. Jiang, L.; Folmer, H.; Ji, M. The drivers of energy intensity in China: A spatial panel data approach. China Econ. Rev. 2014, 31, 351-360.

5. Bilgen, S. Structure and environmental impact of global energy consumption. Renew. Sustain. Energy Rev. 2014, 38, 890-902.

6. Wang, Z.; Lu, M. An empirical study of direct rebound effect for road freight transport in China. Appl. Energy 2014, 133, 274-281.

7. Lai, K.-H.; Wong, C.W.Y.; Cheng, T.C.E. Ecological modernisation of Chinese export manufacturing via green logistics management and its regional implications. Technol. Forecast. Soc. Chang. 2012, 79, 766-770.

8. Zhang, G.; Zhao, Z. Green Packaging Management of Logistics Enterprises. Phys. Proc. 2012, 24, 900-905.

9. Chin, T.A.; Tatb, H.H.; Sulaiman, Z. Green Supply Chain Management, Environmental Collaboration and Sustainability Performance. Proc. CIRP 2015, 26, 695-699.

10. Kuei, C.-H.; Madu, C.N.; Chow, W.S.; Chen, Y. Determinants and associated performance improvement of green supply chain management in China. J. Clean. Prod. 2015, 95, 163-173.

11. Gunasekaran, A.; Subramanian, N.; Rahman, S. Green supply chain collaboration and incentives: Current trends and future directions. Transp. Res. Part E 2015, 74, 1-10.

12. Sheu, J.-B.; Chou, Y.-H.; Hu, C.-C. An integrated logistics operational model for green-supply chain management. Transp. Res. Part E 2005, 41, 287-313.

13. Zhang, N.; Wei, X. Dynamic total factor carbon emissions performance changes in the Chinese transportation industry. Appl. Energy 2015, 146, 409-420.

14. Fahimnia, B.; Sarkis, J.; Eshragh, A. A tradeoff model for green supply chain planning: A leanness-versus-greenness analysis. Omega 2015, 54, 173-190.

15. Kellner, F.; Igl, J. Greenhouse gas reduction in transport: Analyzing the carbon dioxide performance of different freight forwarder networks. J. Clean. Prod. 2015, 99, 177-191.

16. Wei, Q.; Zhao, S.; Xiao, W. A Quantitative Analysis of Carbon Emissions Reduction Ability of Transportation Structure Optimization in China. J. Transp. Syst. Eng. Inf. Technol. 2013, 13, 10-17.

17. Song, D.-P.; $\mathrm{Xu}, \mathrm{J}$. An operational activity-based method to estimate $\mathrm{CO}_{2}$ emissions from container shipping considering empty container repositioning. Transp. Res. Part D 2012, 17, 91-96.

18. He, D.; Liu, H.; He, K.; Meng, F.; Jiang, Y.; Wang, M.; Zhou, J.; Calthorpe, P.; Guo, J.; Yao, Z.; et al. Energy use of, and $\mathrm{CO}_{2}$ emissions from China's urban passenger transportation sector-Carbon mitigation scenarios upon the transportation mode choices. Transp. Res. Part A 2013, 53, 53-67.

19. Yin, X.; Chen, W.; Eom, J.; Clarke, L.E.; Kim, S.H.; Patel, P.L.; Yu, S.; Kyle, G.P. China's transportation energy consumption and $\mathrm{CO}_{2}$ emissions from a global perspective. Energy Policy 2015, 82, 233-248.

20. Hu, J.-L.; Wang, S.-C. Total-factor energy efficiency of regions in China. Energy Policy 2006, 34, 3206-3217.

21. Zheng, L.; Lingying, P.; Feng, F.; Pei, L.; Linwei, M.; Amorelli, A. China's regional disparities in energy consumption: An input-output analysis. Energy 2014, 78, 426-438. 
22. Caraiani, C.; Lungu, C.I.; Dascălu, C. Energy consumption and GDP causality: A three-step analysis for emerging European countries. Renew. Sustain. Energy Rev. 2015, 44, 198-210.

23. Lean, H.H.; Huang, W.; Hong, J. Logistics and economic development: Experience from China. Transp. Policy 2014, 32, 96-104.

24. Lindsey, C.; Mahmassani, H.S.; Mullarkey, M.; Nash, T.; Rothberg, S. Regional logistics hubs, freight activity and industrial space demand: Econometric analysis. Res. Transp. Bus. Manag. 2014, 11, 98-104.

25. $\mathrm{Hu}, \mathrm{K}$; Gan, X.-Q.; Gao, K. Co-integration Model of Logistics Infrastructure Investment and Regional Economic Growth in Central China. Phys. Proc. 2012, 33, 1036-1041.

26. Duan, H.-B.; Zhu, L.; Fan, Y. Optimal carbon taxes in carbon-constrained China: A logisticinduced energy economic hybrid model. Energy 2014, 69, 345-356.

27. Rivera, L.; Sheffi, Y.; Welsch, R. Logistics agglomeration in the US. Transp. Res. Part A 2014, 59, $222-238$.

28. Heuvel, F.P.V.D.; Langen, P.W.D.; Donselaar, K.H.V.; Fransoo, J.C. Regional logistics land allocation policies: Stimulating spatial concentration of logistics firms. Transp. Policy 2013, 30, 275-282.

29. Pan, H.; Zhang, H.; Zhang, X. China's provincial industrial energy efficiency and its determinants Math. Comput. Model. 2013, 58, 1032-1039.

30. Lin, B.; Du, K. Exploring energy efficiency in China's iron and steel industry: A stochastic frontier approach. Energy Policy 2014, 72, 87-96.

31. Howard, B.; Parshall, L.; Thompson, J.; Hammer, S.; Dickinson, J.; Modi, V. Spatial distribution of urban building energy consumption by end use. Energy Build. 2011, 45, 141-151.

32. Spreng, D. Distribution of energy consumption and the $2000 \mathrm{~W} /$ capita target. Energy Policy 2005, 33, 1905-1911.

33. Cardozo, O.D.; García-Palomares, J.C.; Gutiérrez, J. Application of geographically weighted regression to the direct forecasting of transit ridership at station-level. Appl. Geogr. 2012, 34, $548-558$.

34. Wang, W.; Ying, Y.; Wu, Q.; Zhang, H.; Ma, D.; Xiao, W. A GIS-based spatial correlation analysis for ambient air pollution and AECOPD hospitalizations in Jinan, China. Respiratory Med. 2015, 109, 372-378.

35. Dujardin, S.; Marique, A.-F.; Teller, J. Spatial planning as a driver of change in mobility and residential energy consumption. Energy Build. 2014, 68, 779-785.

36. Li, Y.; Li, C.-K.; Tao, J.-J.; Wang, L.-D. Study on Spatial Distribution of Soil Heavy Metals in Huizhou City Based on BP-ANN Modeling and GIS. Proc. Environ. Sci. 2011, 10, 1953-1960.

37. Mu, J.; Luo, N.; Chang, W.; Huang, K.; Shi, M. Predicting and mapping the spatial distribution of Chamaecyparis formosensis in central Taiwan in a GIS with species distribution models. Acta Ecol. Sin. 2013, 33, 325-331.

38. Villarino, S.H.; Studdert, G.A.; Laterra, P.; Cendoya, M.G. Agricultural impact on soil organic carbon content: Testing the IPCC carbon accounting method for evaluations at county scale. Agric. Ecosyst. Environ. 2013, 185, 118-132.

39. Mishra, U.; Torn, M.S.; Masanet, E.; Ogle, S.M. Improving regional soil carbon inventories: Combining the IPCC carbon inventory method with regression kriging. Geoderma 2012, 189-190, 288-295. 
40. Energy Statistics Division of State Statistics Bureau. China Energy Statistical Yearbook; China Statistics Press: Beijing, China, 2012.

41. State Statistics Bureau. China Statistical Yearbook; China Statistics Press: Beijing, China, 2012.

(C) 2015 by the authors; licensee MDPI, Basel, Switzerland. This article is an open access article distributed under the terms and conditions of the Creative Commons Attribution license (http://creativecommons.org/licenses/by/4.0/). 